\title{
Development on Foreign Trade of Beijing's Cultural Industry
}

\author{
Dong Tong ${ }^{1, *}$ \\ ${ }^{1}$ School of Economics and Management, Beijing Institute of Graphic Communication, Beijing, China
}

\begin{abstract}
Since the 19th National Congress of the Communist Party of China, cultural and creative industry has become more and more important in national economic development. Cultural and creative industry plays an important role in promoting economic development, prosperity and rejuvenation in both countries and regions. Beijing is in the key stage of the construction of the national cultural center, and the foreign trade of cultural and creative industry is an important aspect of the construction of the national cultural center. Based on the analysis of the current situation of Beijing's cultural and creative industry, this paper points out three urgent problems in the foreign trade of Beijing's cultural and creative industry from the micro and macro aspects. They are small scale, single form, and the pattern has not yet formed. Finally, the paper puts forward suggestions on the foreign trade of Beijing's cultural and creative industry: expand the international market, promote foreign investment of cultural enterprises, and form a new pattern of factor market and product market of cultural and creative industry.
\end{abstract}

\section{Introduction}

Beijing, as the cultural center of China, is endowed with the historical responsibility of undertaking the spread of Chinese culture on the basis of the functional orientation of the capital city, and is the main position of industrialization and internationalization of Chinese culture. Especially since the $1990 \mathrm{~s}$, the state has promulgated a number of policies, laws and regulations related to the foreign trade of cultural and creative industry. The Beijing Municipal Government has also formulated and implemented a series of cultural trade policies, such as incentives and subsidies for the export of cultural products and services, tax incentives, investment and financing, system reform and service guarantee. With the gradual development of the construction of Beijing National Cultural Center, the pace of foreign trade of Beijing's cultural and creative industry is accelerating, and remarkable achievements have been made.

Based on the functional orientation of the capital city for the construction of the national cultural center, Beijing's cultural and creative industries have formulated and issued relevant policies to support the foreign trade of cultural and creative industry in terms of special fund support, preferential tax policies, financing guarantee, attracting talents and attracting investment.

\section{The Defects of Foreign Trade in Beijing's Cultural and Creative Industry}

\subsection{The total scale of foreign trade in cultural and creative industry}

The report of the 19th National Congress of the Communist Party of China pointed out that the main social contradictions in China have been transformed into the contradiction between the people's growing needs for a better life and the unbalanced development. In the new era, the construction of Beijing's national cultural center promotes Beijing's cultural and creative industry to enter the international market. Since 2012, although the method of customs statistics has changed, it can be seen from the customs comparison data that the export value of cultural products generally showed a trend of first increasing and then decreasing. The export value of cultural products continued to grow in 20122016. In 2013, the export growth rate of cultural products reached $84.95 \%$. However, from 2017 to 2018 , the export volume of Beijing's cultural products showed a negative growth, with the growth rate of $-10.20 \%$ in 2017 and $-30.00 \%$ in 2018. In 2019, the export of cultural products increased by $119.86 \%$ compared with 2018 , and the export volume reached 909.6708 million dollars.

\footnotetext{
${ }^{*}$ Corresponding author: td1202013@sina.cn
} 


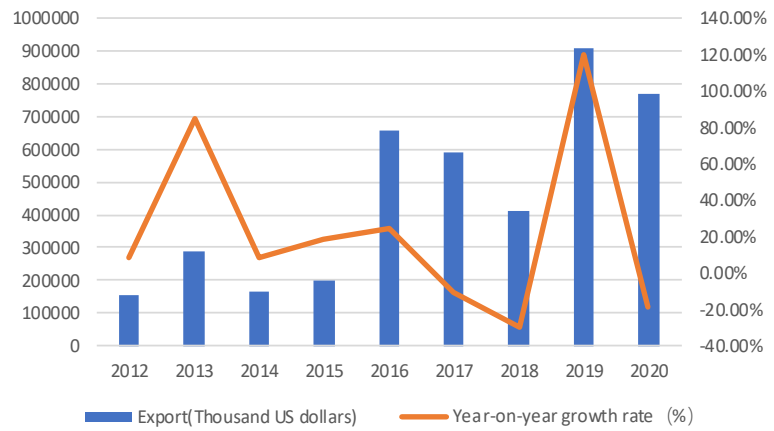

Fig. 1. The export volume of cultural products in Beijing from 2012 to 2020 and its year-on-year growth rate

From the year-on-year growth rate data from January 2019 to December 2019, compared with the same period from January 2018 to December 2018, the growth rate in four months was negative. The maximum value appears in October 2019, with a year-on-year growth rate of $51.32 \%$. The year-on-year growth rate of other eight months is positive, and the maximum value appears in December 2019, with a year-on-year growth rate of $542.60 \%$. From the data of the month on month growth rate from January 2019 to December 2019, the month on month growth rate of six months is negative, and the maximum value appears in February 2019, with the month on month growth rate of $-58.81 \%$. The month on month growth rate of the other six months is positive, and the maximum value appears in November 2019, with a month on month growth rate of $482.28 \%$.

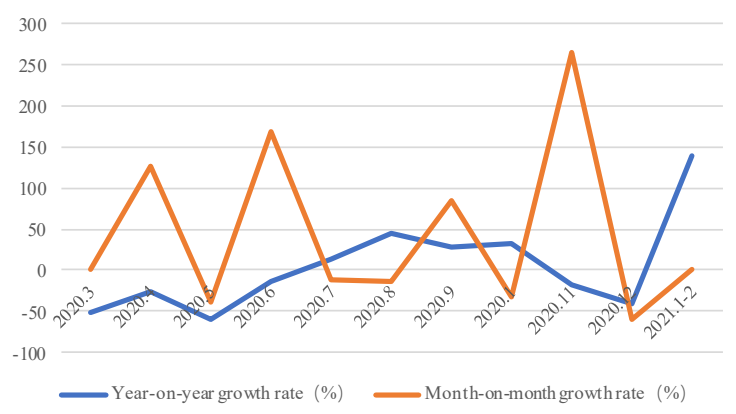

Fig. 2. Beijing cultural products export volume and growth rate from March 2020 to February 2021

\subsection{The foreign trade of the segmentation of cultural and creative industry}

2006 is regarded as the first year of the development of Beijing's cultural and creative industry. Since 2006, the scale of Beijing's cultural and creative industry has been growing. Although some cultural and creative products and enterprises have gone to the international market, their international competitiveness is not strong. The segmentation of cultural and creative industry such as film and television, publishing, performing arts, animation and games are the key areas for Beijing's cultural and creative industry in foreign trade.

\subsubsection{The film and television industry}

Beijing Film and television industry has formed market influence and market competitiveness. However, the financial strength, creative level and overseas marketing channels have not yet been mature. In particular, compared with the world-famous film and television giants, Beijing's film and television industry is difficult to enter the international market.

From the awards of the three major film festivals, we can see that the evaluation of Beijing films in the international market is not high. However, compared with other regions in China, Beijing film has certain advantages in the process of entering the international market. From 1988 to 2018, Chinese films won 10 awards at Cannes Film Festival. Among them, the films produced by Beijing won 7 awards, accounting for $70.00 \%$ of the total number of award-winning films. Chinese films won 18 awards at the Berlin Film Festival. Among them, the films produced by Beijing won 11 awards, accounting for $61.11 \%$ of the total number of award-winning films. Chinese films won 11 awards at the Venice Film Festival. Among them, the films produced by Beijing won 6 Awards, accounting for $54.55 \%$ of the total number of award-winning films. For Beijing Film and television industry, foreign trade has a long way to go.[1]

\subsubsection{The publishing industry}

Beijing is the main export area of Chinese publications. Every year, the number of book copyright exports accounts for about $60 \%$ of the National book copyright exports, and most of the large publishing groups are concentrated in Beijing. In terms of export scale, in 2017, the copyright export volume of five major publishing groups in Beijing accounted for $37.82 \%$ of Beijing's book copyright export volume.

In terms of the number of copyright exports of individual publishing houses, the number of copyright exports of the top 15 individual publishing houses in Beijing accounted for $54.80 \%$ of the total number in 2017. In addition, 19 individual publishing houses accounted for more than $2.00 \%$ of the total export volume of book copyright, accounting for $63.92 \%$ of the total export volume. There are 27 individual publishing houses exporting more than 100 book copyrights, accounting for $78.36 \%$ of the total.

From the language of book export, the main export languages of Chinese book copyright are Korean, Japanese, English, French, German and Russian. In contrast, the main languages of publications exported in Beijing are Arabic, Vietnamese, Thai, Korean, Russian, Japanese and Kyrgyz. The top nine languages of copyright export in Beijing account for $69.59 \%$ of the total copyright export.

In terms of the types of copyright export, the types of copyright export in Beijing are literature, children, culture, art, education, science and technology, economy, politics, language and social sciences. The total export volume of these 10 types of publications accounted for $91.00 \%$ of the total export volume. 


\subsubsection{The performances industry}

Beijing's performances industry takes the opportunity to cooperate with leaders' visits and major diplomatic activities. In Beijing's cultural and creative industry, the number of people who participate in foreign cultural exchanges and visits shows an increasing trend. It increased from 1864 in 2010 to 3956 in 2016, and then dropped to 2716 in 2017.[2]

With the further opening of the performances market, Beijing's performances industry has stepped up the pace of internationalization. Moreover, it has increasingly extensive contacts with large international performing agencies, not only "going out", but also "bringing in".

The drama "the legend of mark polo" won two awards from the Branson Arts Council: the best drama and the best dance team. Shanshui ShengDian Cultural Industry Co., Ltd. and Vietnam cultural management performance Co., Ltd. signed cooperation agreements on live performance in five places of Vietnam (Hanoi, Vinh Ha Long, Phu Quoc Island, Da Nang and Hoi An). The cooperation and exchanges between Beijing's performances industry and those of central and Eastern European countries are also deepening. Among the 40 key cultural trade and investment projects announced by the Ministry of culture in 2018, nine of them belong to Beijing, and three of them belong to the performances industry.[3]

\subsubsection{The animation and game industry}

Since 2018, with the development of China's domestic game market, the market space is gradually saturated. There is a bottleneck in the development of animation and game industry. Subsequently, a large number of animation and game companies began to expand the international market. In this trend, Beijing animation and game industry is actively exploring overseas markets, and its competitiveness in the international market is constantly improving.

Among the top five animation and game companies in overseas market development, Beijing accounts for two of them. From the statistical data, from 2014 to 2018, the export value of Beijing's animation and game industry increased with the increase of output value. The export value of animation and game products increased from 4.230 billion yuan in 2014 to 18.247 billion yuan in 2018 , an increase of $331.37 \%$. It has maintained growth for five consecutive years, of which the export value of animation and game industry accounted for the highest proportion of output value in 2018, accounting for $25.70 \%$.[4]

\section{The Deficiency of Foreign Trade in Beijing's Cultural and Creative Industry}

\subsection{The scale of export is much smaller than that of import}

In 2018, the total import and export volume of cultural products in Beijing was about 2.287 billion U.S. dollars, of which the import value of cultural products was about 1.873 billion U.S. dollars, the export value of cultural products was about 414 million U.S. dollars, and the net export value was about-1.459 billion U.S. dollars. The export ability of cultural and creative industry is very weak. Especially from the data of 2016-2018, the export value of cultural and creative products has been shrinking for three years. At the same time, the scale of net exports is gradually increasing, and the scale of cultural exports is gradually expanding compared with cultural imports. In 2016, the scale of net exports was about 740 million US dollars, and the import value was about 2.13 times of the export value. In 2017, the net export scale was about 913 million US dollars, and the import value was about 2.54 times of the export value. In 2018, the net export scale was about 1.459 billion US dollars, and the import value was about 4.53 times of the export value. The export scale of Beijing's cultural and creative industry is one of the important factors that restrict the foreign trade of Beijing's cultural and creative industry.

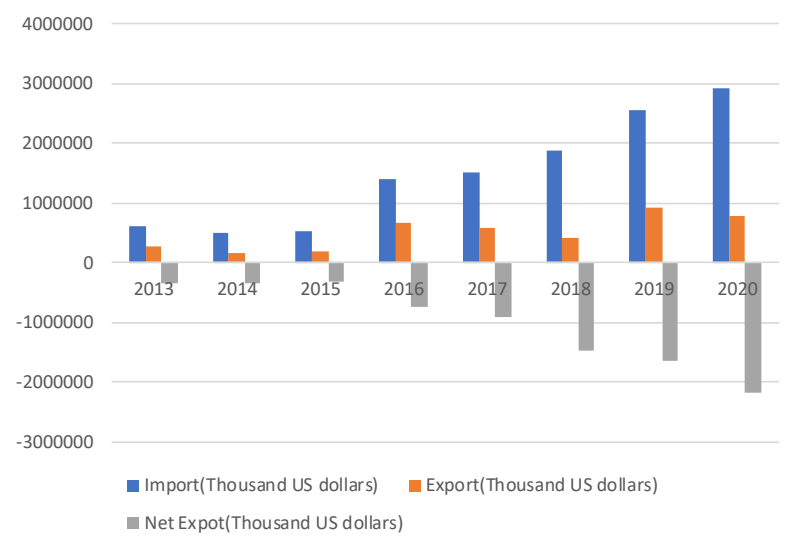

Fig. 3. Import and export scale of cultural and creative products in Beijing from 2013 to 2020

\subsection{The single export format}

Beijing's foreign trade of cultural and creative industries focuses on trade rather than investment. Although the export scale of Beijing's cultural and creative industries is very small, and the export products and services are very limited, compared with this, the scale of foreign investment is insignificant. With the development of China's economy and the transformation and upgrading of the economic structure, foreign direct investment is an effective way for the cultural industry to enter the international market. The Belt and Road Initiative provides a great policy support for Beijing's cultural and creative industry to move towards the international market. China's huge economic scale creates huge external market space, which stimulates the strong demand of foreign markets for Chinese culture. The pace of foreign investment in Beijing's cultural and creative industry needs to be improved. Nevertheless, there is still a huge space for Beijing's cultural and creative industry to expand its foreign investment. This is not only in the 
field of media, but also in publishing, film, performance and other industries.

\subsection{Foreign trade pattern of cultural and creative industries has not been formed}

As a national cultural center, Beijing is responsible for promoting cultural exchanges between China and foreign countries. The report of the 19th National Congress of the Communist Party of China reinterpreted the main social contradictions in China, and the role of cultural and creative industry in economic and social development was further highlighted. In 2016, based on the Opinions on Accelerating the Development of Foreign Cultural Trade and related policies, the Beijing Municipal People's Government issued the Implementation Opinions on Accelerating the Development of Foreign Cultural Trade to speed up the construction of the national foreign cultural trade base (Beijing). In 2017, "Beijing Urban Master Plan (20162035)" proposed to give play to the demonstration and leading role of the national foreign cultural and trade base.[5]

\section{Suggestions on Foreign Trade of Cultural and Creative Industries in Beijing}

\subsection{Relying on the Belt and Road Initiative to expand the scale of foreign trade}

To serve the construction of Beijing's national cultural center and improve the level of "four services", under the initiative of promoting the Belt and Road Initiative co-construction plan. The foreign trade of Beijing's cultural and creative industry should expand overseas markets, especially the cultural product markets of countries (regions) along the Belt and Road Initiative, and build a cultural platform with world influence. On the basis of overall planning and scientific layout of cultural and creative industry, highlight the dissemination of Beijing's cultural connotation, and focus on expanding the market around core cultural fields such as film and television industry, publishing industry, performances industry and animation and game industry.

Based on the foreign trade platform of cultural and creative industry, promote and build the cultural exchange platform based on large-scale international cultural events, such as Beijing International Film Festival, Beijing International Book Festival, Beijing International Music Festival, Beijing cultural fair, etc. With the implementation of the Belt and Road Initiative, not only the economic exchanges with these countries (regions) have been strengthened, but also the people of these countries (regions) have become more and more eager to understand Chinese culture and Chinese people's way of life. Therefore, the demand for Chinese cultural products and services is also increasing. This is an opportunity for Beijing's foreign trade of cultural and creative industry, especially the establishment of the " 10 + 1" cooperation mechanism between China and ASEAN, and the "16 + 1" cooperation mechanism between China and central and Eastern Europe, which provides a bridge for Beijing's foreign trade of cultural and creative industry to achieve cultural market docking with Southeast Asia and Europe. At the same time, taking the construction of the national cultural center as an opportunity, we should seize the opportunity of leaders' visits to expand the international market of Beijing performances.

\subsection{Promote capital export}

The biggest breakthrough of foreign trade in Beijing's cultural and creative industries is the Belt and Road Initiative countries. The Belt and Road Initiative involves 65 countries (regions) in South Asia, Southeast Asia, Central Asia, West Asia, central and Eastern Europe and North Africa. This region has a wide coverage and large market space. Its GDP accounts for about $30 \%$ of the world's total, and its population is about 4.4 billion.

In the area of foreign investment, we should continue to promote investment in existing countries and regions, especially Asian countries such as Singapore, Malaysia, India, United Arab Emirates, Indonesia, Thailand, and other countries such as Russia and Australia. On the other hand, it is necessary to expand new investment target countries and strengthen investment in cultural and creative industry in countries along the Belt and Road Initiative.

At the same time, with the help of financing channels, reasonable distribution should be carried out in the Belt and Road Initiative countries. According to the inherent development law of cultural and creative industry, Beijing's cultural and creative industry capital should be promoted to the international market, the capital docking with the Silk Road Fund and the Silk Road cultural commonweal fund should be actively promoted, the docking of Beijing's cultural and creative enterprises with the BRICs Development Bank, the Asian infrastructure investment bank and other international financial institutions should be promoted, and the cooperation with the proposed countries (regions) should be established Investment relationship.

\subsection{Promote the formation of foreign trade pattern of cultural and creative industry}

The development of cultural and creative industry should be planned from a macro perspective. It is extremely urgent to form a new pattern of foreign trade of Beijing's cultural and creative industry with the construction of national cultural centers, the coordinated development of Beijing-Tianjin-Hebei and the Belt and Road Initiative as the core. The foreign trade of Beijing's cultural and creative industry needs to form a new development pattern in factor market and product market.

From the factor market pattern, Beijing is located at the core of the coordinated development of Beijing- 
Tianjin-Hebei, with obvious advantages in resource endowment. Beijing-Tianjin-Hebei metropolitan area is rich in cultural resources, especially with the promotion of the construction of Beijing's national cultural center, the advantage of the foreign trade of Beijing's cultural and creative industry is further revealed.

From the product market pattern, China is the core of the Belt and Road initiative, and Beijing is also the national cultural center. Beijing has become one of the main export places of cultural and creative industry market under the Belt and Road Initiative. Under the Belt and Road Initiative, the foreign trade of Beijing's cultural and creative industry should form a "point-linesurface" pattern. Take the countries with solid market foundation and broad market space as product markets, and on the basis of stabilizing these markets, further expand the export of cultural products and services to all countries (regions) of the initiative, and then take the initiative countries (regions) as nodes to expand to surrounding countries. Finally, the product market pattern of Beijing's cultural and creative industries' foreign trade will be formed.

\section{Conclusions}

Beijing's foreign trade of cultural and creative industries focuses on supporting the export of film and television, publishing, performing arts, animation and games with Chinese characteristics. There are three main problems in Beijing's cultural trade: the scale of export is much smaller than that of import; the single export format; foreign trade pattern of cultural and creative industries has not been formed. Three suggestions are put forward: relying on the Belt and Road Initiative to expand the scale of foreign trade; promote capital export; promote the formation of foreign trade pattern of cultural and creative industry.

\section{Acknowledgement}

Supported by scientific research projects of Beijing Municipal Commission of Education "The innovation diffusion of Beijing cultural and creative industries and the optimization of the whole industry chain structure" (SM202110015002) and Youth Social Science Talent funding project of Beijing Federation of Social Science Circles "Research on going global of Beijing's cultural and creative industry" (2018QNRC06).

\section{References}

1. J. S. Li, RPT. Intl. CT. M. SSAP, 7-10 (2020)

2. J. C. Zhang, RPT. Cul. Ind. M. SSAP, 224-226 (2020)

3. W. Liu, Dvlp. CT. FCC, J. 55-60 (2017)

4. X. H. Ge, Anal. Intl. CT. CE, M. 6-9 (2018)

5. G. Y. Wang, RPT. Cul. Ind. M. SSAP, 1-29 (2020) 